\title{
LA CALIDAD DEL CAFÉ
}

Valentina Osorio Pérez*

En el café, la calidad se asocia con el compromiso del caficultor en la cadena productiva para lograr una bebida con atributos sensoriales sobresalientes. La calidad del café se determina por un conjunto de características químicas, microbiológicas, físicas y sensoriales que incentivan al consumidor a pagar un precio superior por el producto, lo que representa mejores ingresos para el caficultor. La combinación de las características ambientales (clima y suelo) y los factores humanos, permiten la máxima expresión de las cualidades intrínsecas del café, generando los elementos necesarios para lograr su posicionamiento en el mercado de calidad superior.

Para la evaluación de la calidad de un producto se requiere del conocimiento de las propiedades y cualidades que permiten clasificarlo dentro de los valores de calidad, así como aquello que constituye un defecto o una característica no aceptable para el consumo. El análisis físico y sensorial del café describen las principales características de calidad: granos negros, vinagres, flojos, aplastados y sanos, entre otros, y características sensoriales como aroma, cuerpo, acidez.

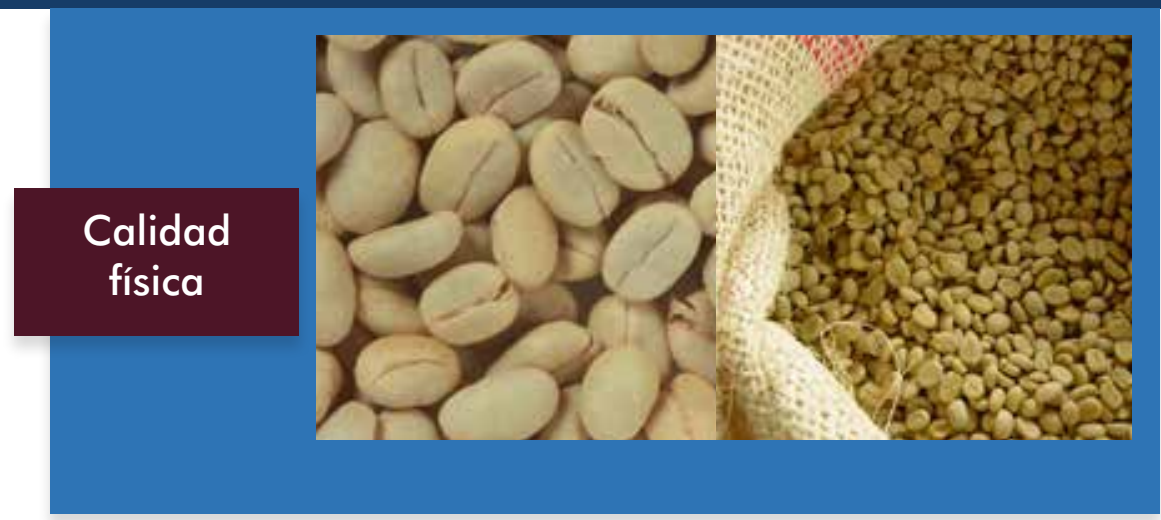

Osorio, V. (2021). La calidad del Café. En Centro Nacional de Investigaciones de Café, Guía más agronomía, más productividad, más calidad (3a ed., pp. 219-234). Cenicafé. https://doi.org/10.38141/10791/0014_12 


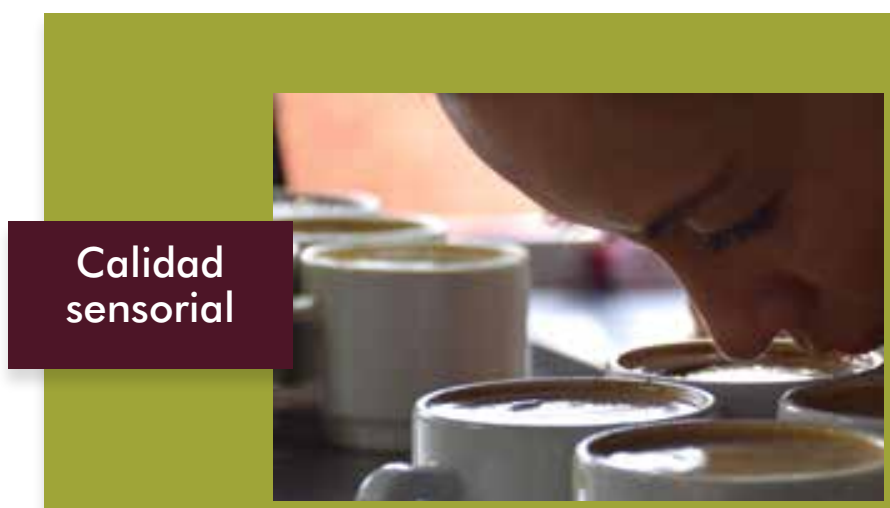

Composición química<smiles>Cn1c(=O)c2c(ncn2C)n(C)c1=O</smiles>

Inocuidad

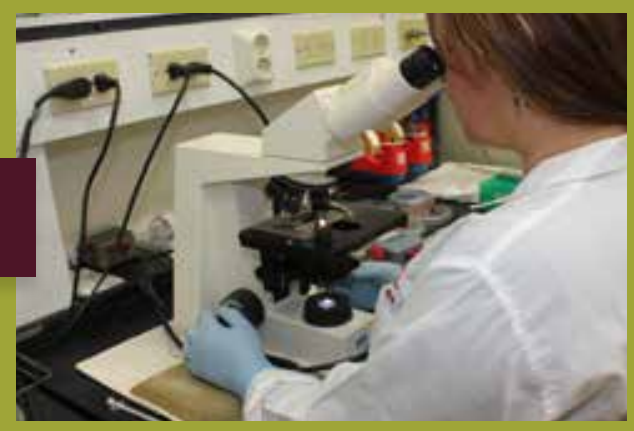


calidad fisica del café

Hace referencia al aspecto visual del café e incluye la valoración del olor y color del pergamino, así como la evaluación de su aspecto general.

Los principales indicadores de calidad física del café pergamino seco son:

Contenido de humedad

\section{Cantidad de almendra sana}

El café pergamino seco está compuesto básicamente por pergamino (endocarpio, cisco), almendra defectuosa y almendra sana.

\section{Café Pergamino seco CPS}

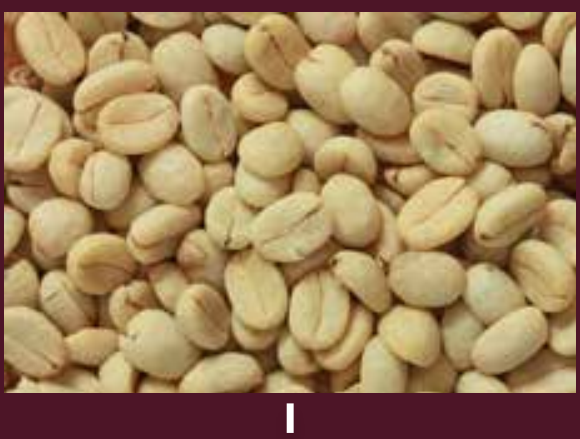

Inspección visual

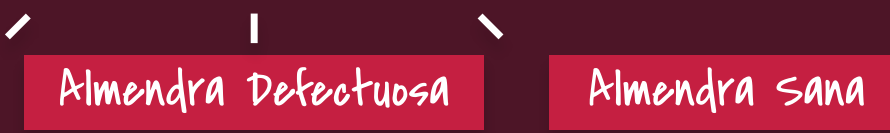

Cisco

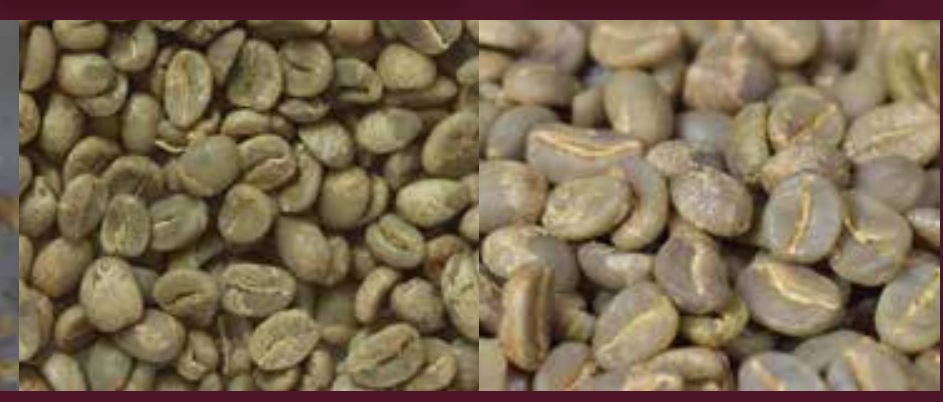


El contenido de humedad en el café juega un papel importante en la vida útil del producto y durante el almacenamiento. Un alto contenido de humedad puede afectar la calidad del grano, debido a que produce el calentamiento de la masa y genera focos de hongos e insectos. Los granos cereales con contenidos de humedad inferiores al $13 \%$ son poco susceptibles al ataque de microorganismos en cualquier medio. El contenido de humedad del café debe encontrarse en un rango del $10 \%$ al $12 \%$.

La actividad de agua expresa la disponibilidad potencial del agua y está fuertemente relacionada con el tipo de producto, su composición química y con la temperatura de los granos. Para el café pergamino seco y excelso, bajo las mismas condiciones ambientales, cuanto mayor sea el contenido de agua, mayor será la actividad de agua. Este parámetro no es un indicador de la distribución del agua dentro del grano. El proceso de secado de café que asegura contenidos de humedad comprendidos entre el $10 \%$ al $12 \%$, elimina el agua disponible y deja solo el agua ligada, permitiendo que los valores de actividad de agua sean inferiores a 0,62.

\section{Valoración de la calidad física para la compra de café}

En Colombia se cuenta con dos formas de valoración: el porcentaje de almendra sana y el factor de rendimiento.

El porcentaje de almendra sana se refiere a la cantidad de granos sanos, sin defectos, presente en una cantidad determinada de café. El valor promedio se estima en $74 \%$, y valores superiores indican una mejor calidad física.

Por su parte, el factor de rendimiento se define como la cantidad de café pergamino seco que se necesita para obtener un saco de $70 \mathrm{~kg}$ de café excelso. Actualmente, el promedio del factor de rendimiento en el país es de $94 \mathrm{~kg}$ de café pergamino seco para obtener 70 kilogramos de café excelso. Lo restante, corresponde a cisco $(18,7 \mathrm{~kg})$ y almendra defectuosa $(5,3 \mathrm{~kg})$. De esta manera, el precio obtenido en la comercialización depende de la calidad del café que se lleve al punto de compra. 
Según la Resolución No.2 del Comité Nacional de Cafeteros 25/ IV/2016, los defectos del café verde se clasifican en defectos del primer y segundo grupo.

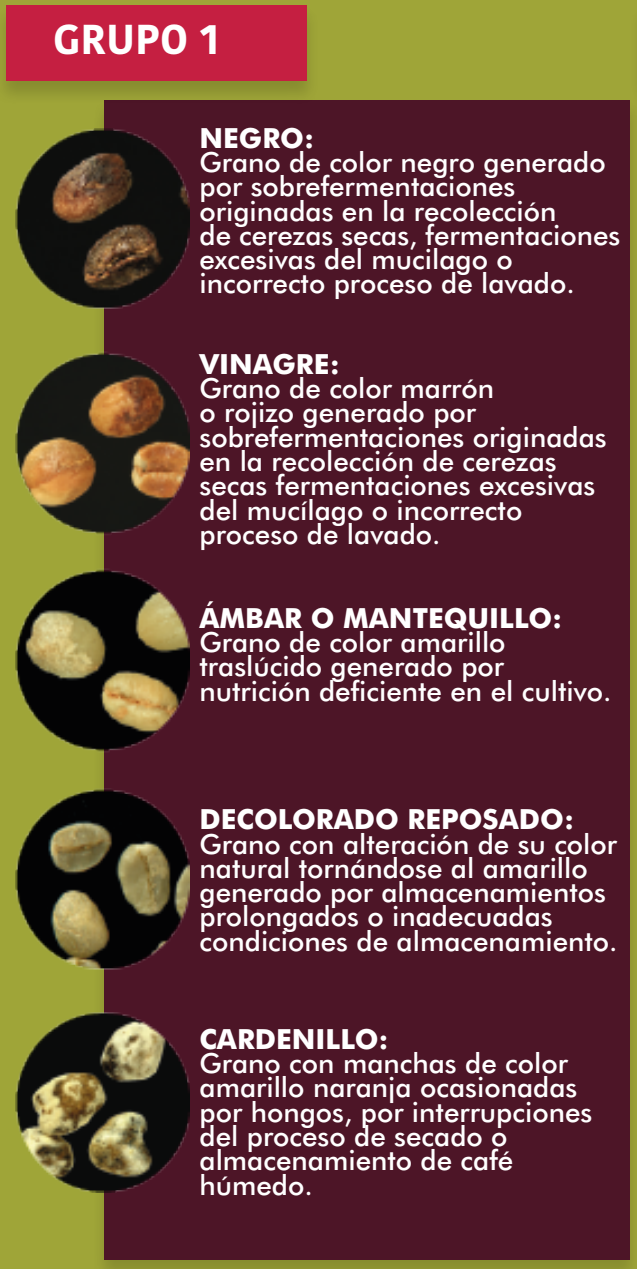

\section{GRUPO 1}

\section{NEGRO:}

Grano de color negro generado taciones excesivas del mucilago 0

VINAGRE:

Grano de color marrón o rolizo generado por

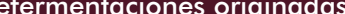
secas fermentaciones excesivas del mucílago o incorrecto proceso de lavado.

ÁMBAR O MANTEQUILLO: Grano de color amarillo raslúcido generado por trutricion deficiente en el cultivo.

\section{DECOLORADO RFPOSADO:}

ru color prolongados o inadecuadas condiciones de almacenamiento.

\section{CARDENILLO:} proceso de secado almacenamiento de café húmedo.

\section{GRUPO 2}

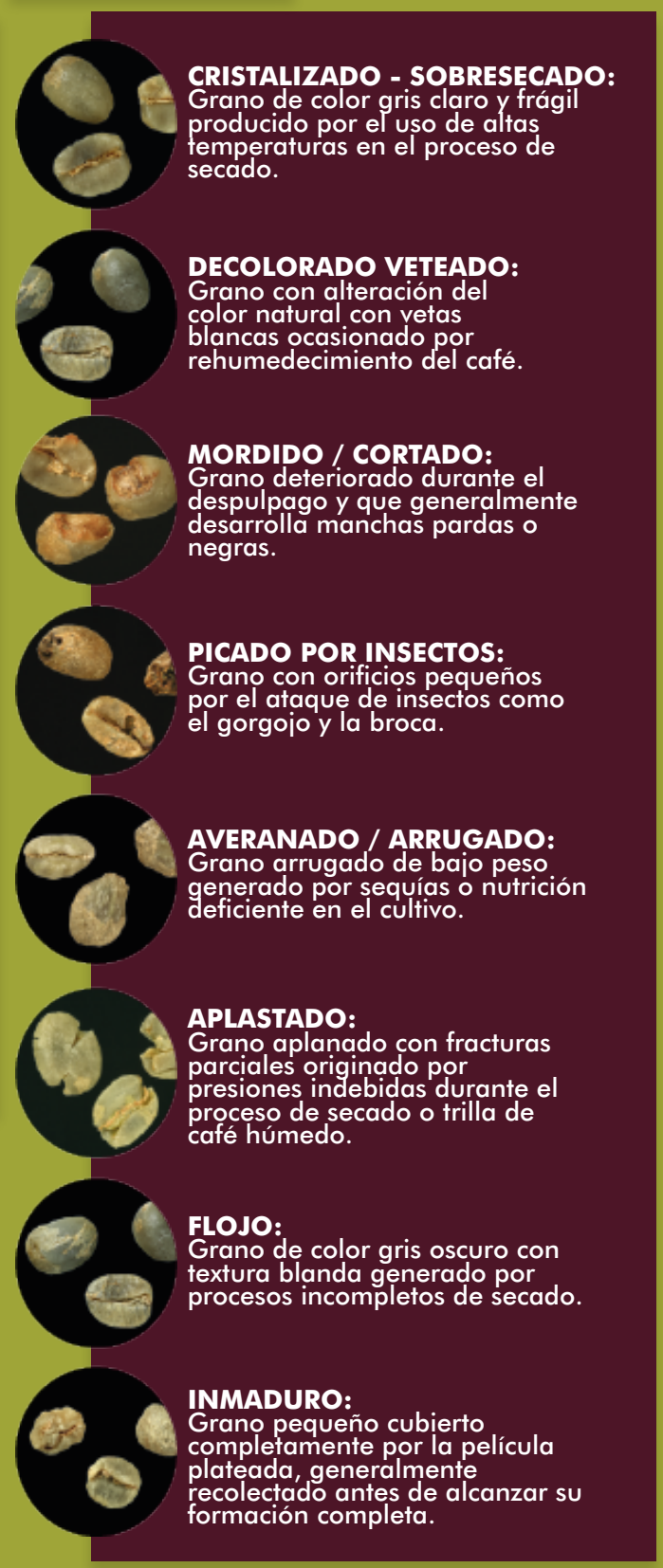




\section{Calidad sensorial del café}

El análisis sensorial, es decir, el estudio de aquellas propiedades de los alimentos que afectan los órganos de los sentidos, es hasta ahora el método más eficiente para evaluar la calidad del café. Las características de color, aspecto, olor y sabor de los alimentos, estimulan la visión, el olfato, el tacto y el gusto, produciendo estímulos que van al cerebro, donde ocurre la percepción y correlación de impresiones sensoriales, que se convierten en un juicio por medio del cual se determina si un producto es aceptado o rechazado.

Existen principalmente dos tipos de análisis sensoriales, los subjetivos y los objetivos. En el primero se evalúa la aceptación de un producto de acuerdo con las preferencias del consumidor, el cual no tiene conocimiento de las características a evaluar. Mientras que, los análisis objetivos son realizados por jueces entrenados, que conocen los diferentes atributos a evaluar, así como la escala de valoración. En el análisis sensorial del café las pruebas analíticas discriminativas son ampliamente usadas para el entrenamiento de catadores y para la generación del perfil de los atributos del café es utilizada la prueba analítica descriptiva QDA o perfil del gusto.

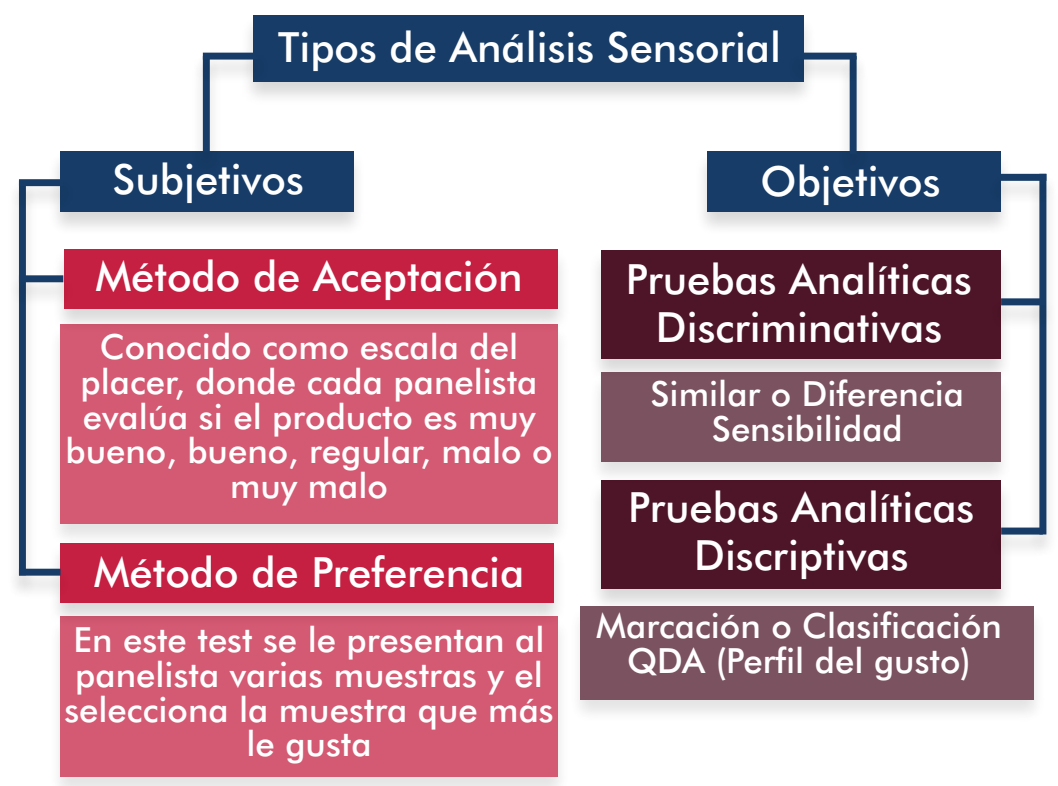


El análisis sensorial de café también es denominado catación y tiene los siguientes objetivos:

$\rightarrow$ Definir si el café tiene defectos o sabores desagradables.

$\rightarrow$ Describir los atributos y los sabores agradables.

$\rightarrow$ Evaluar su intensidad.

$\rightarrow$ Decidir si el café es malo, regular, promedio, bueno, muy bueno o sobresaliente.

$\rightarrow$ Informar sobre los resultados obtenidos.

Los defectos sensoriales más comunes pueden agruparse en cuatro grandes conjuntos por su similitud en el efecto negativo sobre los atributos sensoriales del café. Así, el grupo de los sobrefermentados está asociado a sabores de pulpa descompuesta con predominancia de acidez tipo "agria"; el grupo de los ásperos a sabores residuales pesados; el grupo de los terrosos a sabores dentro del rango de tierra, madera con disminución de la limpieza en el sabor residual; el grupo de los contaminados está asociado a sabores extraños que pueden darse por el contacto del café con agentes externos.

\begin{tabular}{|c|c|c|c|}
\hline Sobrefermentados & Ásperos & Terrosos & Contaminados \\
\hline Pulpa & Inmaduro & Terroso & Fenol \\
\hline Vinagre & Acre & Mohoso & Humo \\
\hline Fermento & Áspero & Reposo & Contaminado \\
\hline Stinker & & & Químico \\
\hline
\end{tabular}




\section{En el siguiente cuadro se presentan las definiciones de los defectos sensoriales en el sabor del café, según la Norma Técnica Colombiana NTC 2758.}

\begin{tabular}{|c|c|c|}
\hline Grupo & Defecto & Definición NTC 2758 \\
\hline \multirow{4}{*}{ 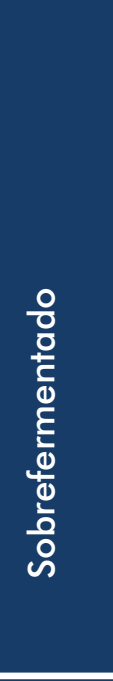 } & Pulpa & $\begin{array}{l}\text { 4.29. Aroma y sabor que da en la bebida un gusto } \\
\text { al fruto de café sobremaduro que evoca el aroma a } \\
\text { la pulpa fresca. }\end{array}$ \\
\hline & Vinagre & $\begin{array}{l}\text { 4.77. Sensación olfativa y gustativa diferente } \\
\text { a la de la acidez natural, caracterizada por } \\
\text { la descomposición intermedia a ácido acético } \\
\text { generalmente ocasionada por una fermentación } \\
\text { excesiva. }\end{array}$ \\
\hline & Fermentado & $\begin{array}{l}\text { 4.48. Sensación olfativa y gustativa a materia } \\
\text { orgánica descompuesta, indeseable en el café. } \\
\text { Producido en la sobrefermentación enzimática de } \\
\text { compuestos orgánicos durante el beneficio. }\end{array}$ \\
\hline & Stinker & $\begin{array}{l}\text { 4.50. Sensación de aroma y sabor fuerte y } \\
\text { defectuoso a materia orgánica putrefacta, se } \\
\text { origina por una excesiva sobrefermentación de } \\
\text { las cerezas del café debido a sobre maduración o } \\
\text { deficientes condiciones de su beneficio. }\end{array}$ \\
\hline \multirow{3}{*}{$\begin{array}{l}\frac{0}{0} \\
\frac{0}{0} \\
\frac{0}{0} \\
\dot{d} \\
\frac{1}{4}\end{array}$} & Acre & $\begin{array}{l}\text { 4.28. Sensación olfativa y gustativa áspera, } \\
\text { amarga, astringente, picante y pesada. Suele estar } \\
\text { asociada a la presencia de granos defectuosos } \\
\text { especialmente negros. }\end{array}$ \\
\hline & Áspero & $\begin{array}{l}\text { 4.36. Sensación táctil fuerte, rasposa y/o tosca } \\
\text { indeseable en el café, causada por presencia de } \\
\text { granos defectuosos, deficiencias en el proceso de } \\
\text { industrialización, deterioro del café tostado y/o } \\
\text { preparación de la bebida. }\end{array}$ \\
\hline & Inmaduro & $\begin{array}{l}\text { 4.53. Percepción de aroma y sabor que puede } \\
\text { ser ocasionada por la presencia de frutos de café } \\
\text { verdes y pintones que producen tazas astringentes, } \\
\text { agresivas y que no tienen características } \\
\text { organolépticas desarrolladas. }\end{array}$ \\
\hline \multirow[t]{2}{*}{ ơ } & Sucio & $\begin{array}{l}\text { 4.73. Sensación de aroma y sabor asociada a } \\
\text { polvo, pesada en el paladar e indeseable en el } \\
\text { café. Originado por deficiencias de la limpieza en } \\
\text { el beneficio y/o almacenamiento del café verde y } \\
\text { pergamino. }\end{array}$ \\
\hline & Paja & $\begin{array}{l}\text { 4.62. Sensación de aroma y sabor característica a } \\
\text { hierba o grama seca y/o heno, puede presentarse } \\
\text { en cafés frescos deficientemente secados o por la } \\
\text { transformación de material orgánico durante su } \\
\text { almacenamiento. }\end{array}$ \\
\hline
\end{tabular}




\begin{tabular}{|c|c|c|}
\hline \multirow{3}{*}{ 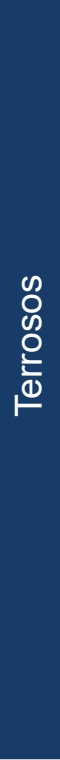 } & Mohoso & $\begin{array}{l}\text { 4.58. Aroma y sabor indeseable del café, } \\
\text { característico a moho que se desarrolla por el } \\
\text { inadecuado manejo de la humedad durante el } \\
\text { beneficio, en especial en el secado del café y } \\
\text { durante su almacenamiento. }\end{array}$ \\
\hline & Terroso & $\begin{array}{l}\text { 4.74. Aroma y sabor a tierra húmeda o recién } \\
\text { movida, indeseable en los cafés arábigos; en } \\
\text { algunos casos se asocia al hollejo de la papa. } \\
\text { Esta característica se puede presentar por un } \\
\text { secado inadecuado del café sobre tierra durante } \\
\text { el beneficio. }\end{array}$ \\
\hline & Reposo & $\begin{array}{l}\text { 4.98. Sabor y aroma característico de café } \\
\text { verde que debido al tiempo y/o condiciones } \\
\text { de almacenamiento han hecho que las } \\
\text { características de aroma y sabor, especialmente } \\
\text { la acidez, hayan disminuido. En el caso de café } \\
\text { fresco esta característica se considera un defecto. } \\
\text { Cuando aparecen leves notas de reposo en un } \\
\text { café la sensación es denominada como ligero } \\
\text { reposo (oldish). }\end{array}$ \\
\hline \multirow{6}{*}{ 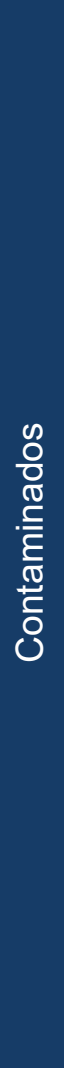 } & Humo & $\begin{array}{l}\text { 4.32. Sensación olfativa asociada a la presencia } \\
\text { de humo que se impregna en el café en cualquier } \\
\text { etapa desde el beneficio hasta la preparación de } \\
\text { la bebida debido a condiciones inadecuadas. }\end{array}$ \\
\hline & Combustible & $\begin{array}{l}\text { 4.42. Característica que presenta el café por } \\
\text { contaminación con derivados del petróleo como } \\
\text { ACPM o gasolina durante su beneficio, transporte, } \\
\text { almacenamiento o torrefacción. }\end{array}$ \\
\hline & Fenol & $\begin{array}{l}\text { 4.47. Aroma y principalmente sabores } \\
\text { indeseables en el café asociado a compuestos } \\
\text { halogenados (con cloro, yodo). Se puede generar } \\
\text { durante el beneficio por lavado con aguas } \\
\text { cloradas o con residuos de desinfectantes o por } \\
\text { rehumedecimiento del café durante el secado. }\end{array}$ \\
\hline & Metálico & $\begin{array}{l}\text { 4.57. Sensación gustativa similar a la que toma } \\
\text { el agua en contacto directo con superficies } \\
\text { metálicas recién pulidas. Indeseable en el café, } \\
\text { puede presentarse por el agua o los recipientes } \\
\text { utilizados en la preparación de la bebida. }\end{array}$ \\
\hline & Químico & $\begin{array}{l}\text { 4.68. Aroma y sabor a compuestos químicos } \\
\text { como desinfectantes o medicinales, característicos } \\
\text { de los hospitales, e indeseables en el café. Se } \\
\text { pueden generar en cafés muy tostados. }\end{array}$ \\
\hline & $\begin{array}{c}\text { Contaminado } \\
\text { No } \\
\text { Identificado }\end{array}$ & $\begin{array}{l}\text { 4.60. Característica de sabor y/o aroma } \\
\text { indeseables en el café que no se puede definir. }\end{array}$ \\
\hline
\end{tabular}


La calidad sensorial del café se rige por protocolos de preparación estandarizada de muestras y de evaluación de los atributos, con el propósito de determinar la percepción por parte de los catadores. Se analizan los atributos y luego se clasifican las muestras en una escala numérica, lo que permite comparar puntajes entre estas. Se espera que los cafés que reciban los puntajes más altos sean los mejores. Este tipo de análisis sensorial es una técnica reproducible para identificar, cuantificar, describir las características de un producto y determinar su calidad. Permite evaluar tanto individual como integralmente las características sensoriales del café y las relaciones entre ellas, obteniéndose la mayor información posible de una muestra. Se definen los principales atributos del café.

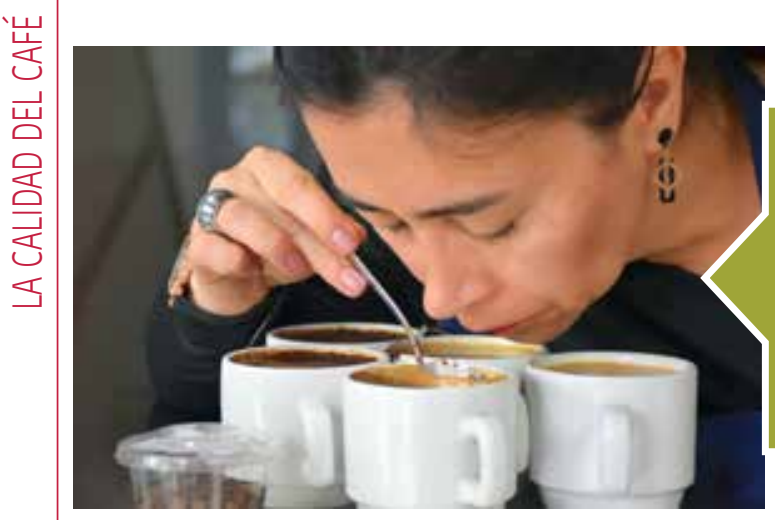

Fragancia / Aroma: Percepción olfativa del café, los aspectos volátiles se incluyen en la fragancia (definida como el olor café de la muestra molida cuando todavía está seca) y los aspectos aromáticos en el aroma (olor café mezclado con agua caliente).

Sabor: El sabor representa la característica principal del café, es una impresión combinada de todas las sensaciones gustativas y aromas retro nasales que van de la boca a la nariz.
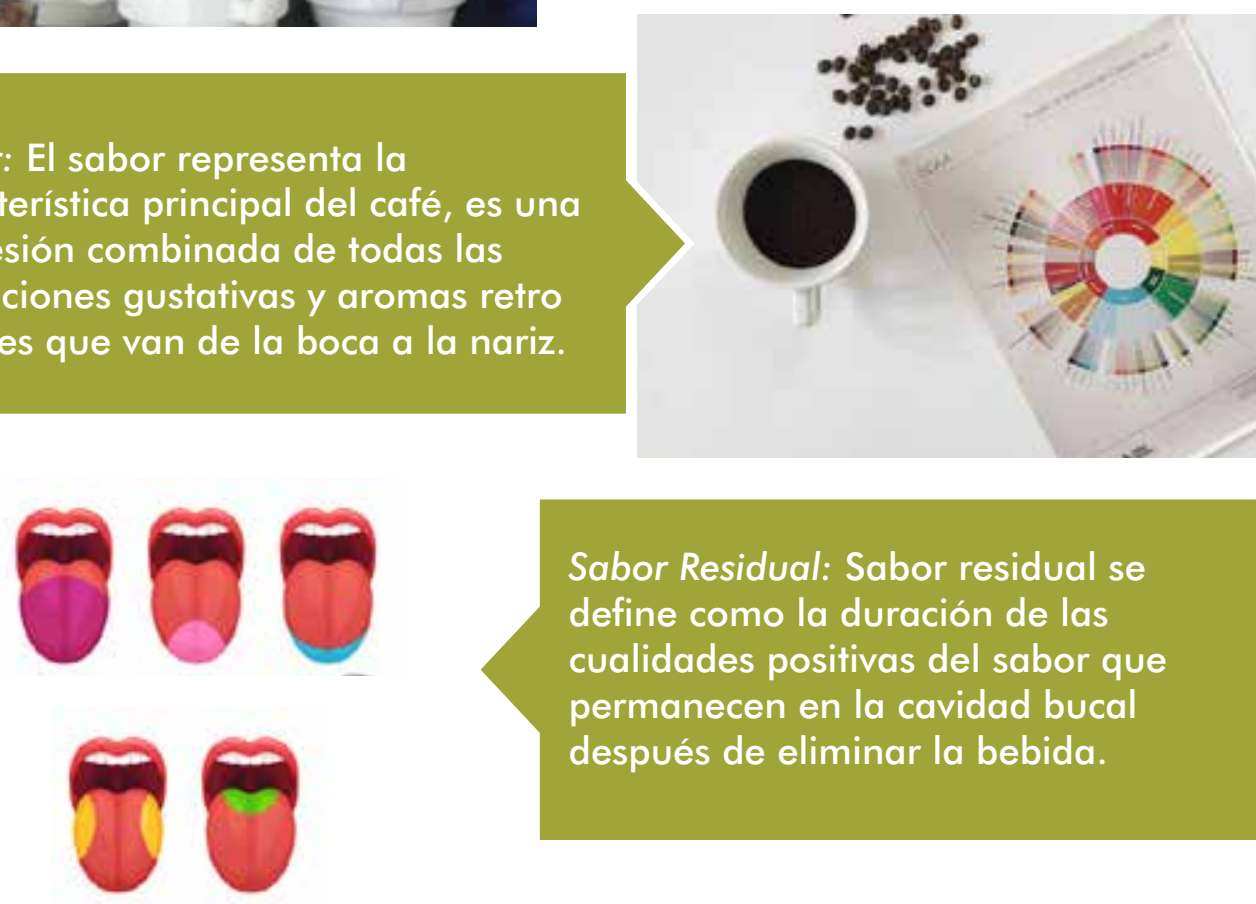

Sabor Residual: Sabor residual se define como la duración de las cualidades positivas del sabor que permanecen en la cavidad bucal después de eliminar la bebida. 
Acidez: La acidez se describe como aquella sensación en la lengua que hace salivar. A menudo se describe como "brillante" cuando es favorable - "agria" cuando es desfavorable.

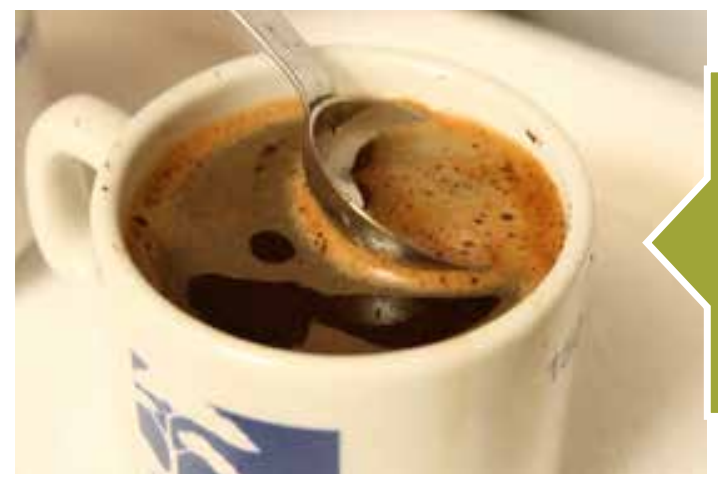

Cuerpo: Sensación de textura asociada al carácter y fuerza de la bebida. La calidad del cuerpo se basa en la sensación de pesadez del líquido en la boca especialmente como se percibe entre la lengua y el paladar superior de la boca.

Balance (o Equilibrio): Como todos los diferentes aspectos del sabor: sabor residual, la acidez y el cuerpo de la muestra trabajan juntos y se complementan, o se contrastan uno al otro, lo resultante es el balance.
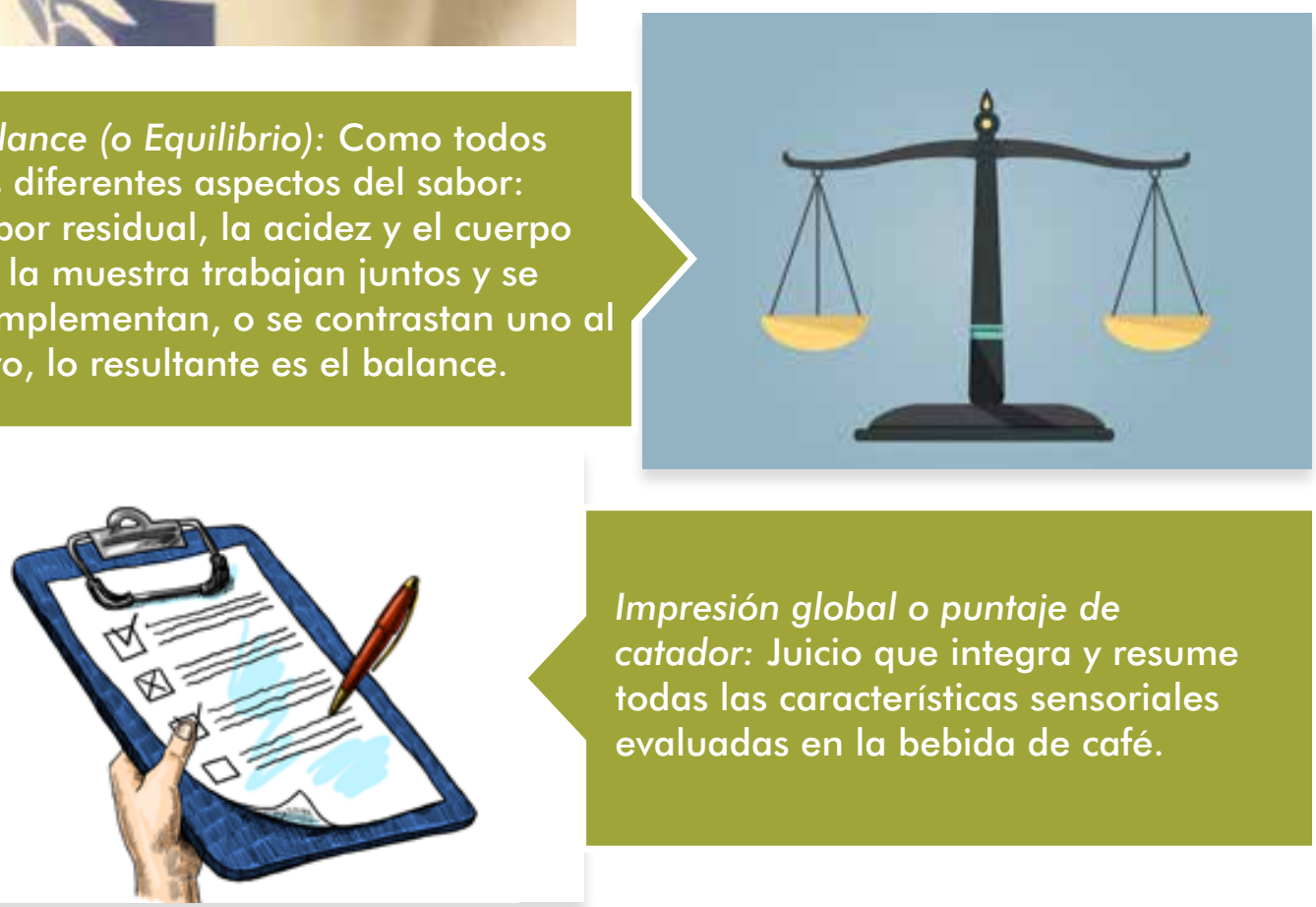

Impresión global o puntaje de catador: Juicio que integra y resume todas las características sensoriales evaluadas en la bebida de café. 
Existen muchas escalas y protocolos para la valoración de la calidad sensorial del café, pero uno de los procedimientos más difundidos es el desarrollado por la Specialty Coffee Association (SCA). El formato de registro provee los medios para registrar 11 atributos del café: Fragancia/aroma, sabor, sabor residual, acidez, cuerpo, balance, defectos y puntaje catador. Para la metodología SCA los atributos de dulzor, taza limpia y uniformidad se evalúan de manera discriminante, es decir, si existen o no en las tazas evaluadas. El dulzor se refiere a una plenitud agradable del sabor, taza limpia a la ausencia de defectos sensoriales y la uniformidad se refiere a la consistencia del sabor entre las tazas de la muestra, si las tazas tienen sabores diferentes, la calificación de este aspecto no será alta. Se muestra la clasificación del café dentro de diferentes rangos de especialidad en función de su puntaje total.

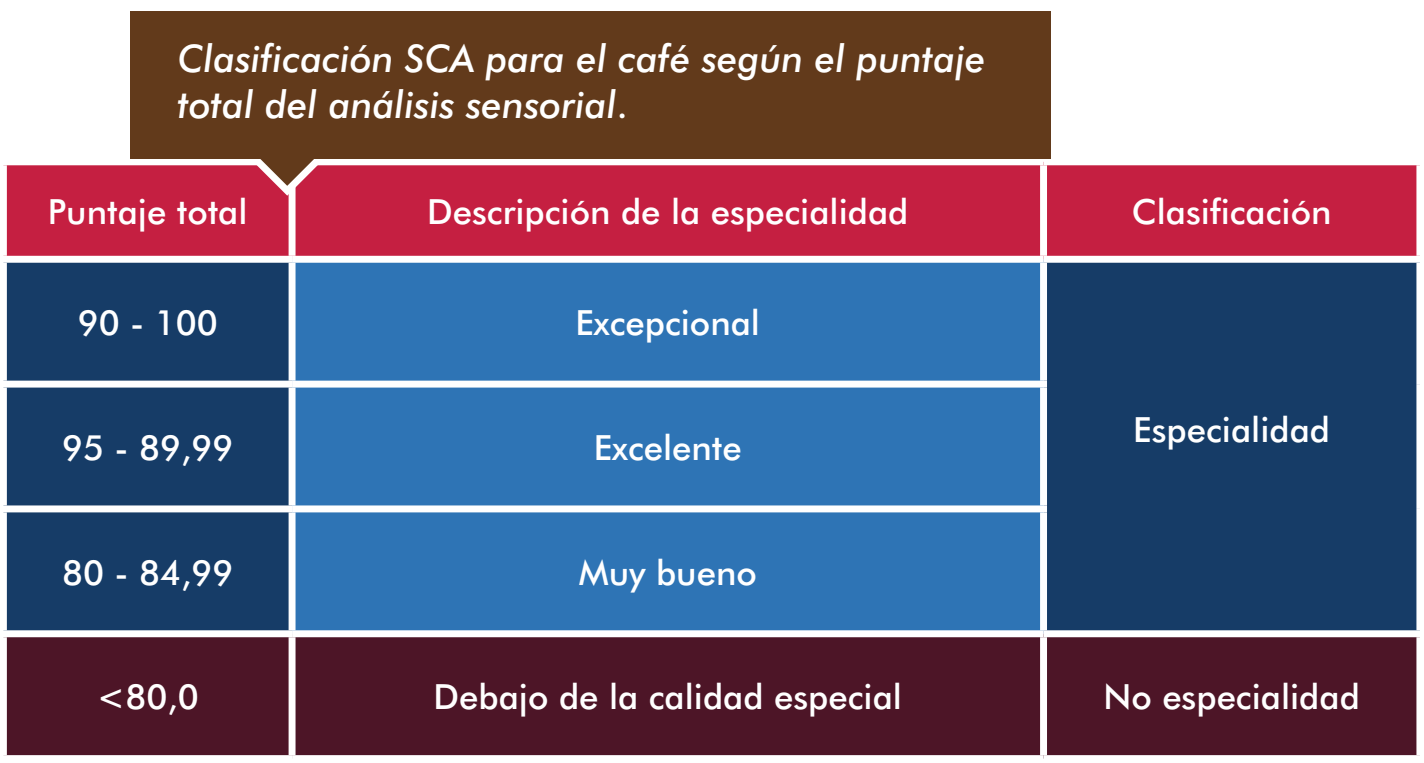

Los atributos sensoriales del café pueden describirse desde su intensidad y calidad en una escala descriptiva. Se presentan algunos atributos sensoriales del café y algunos descriptores positivos y negativos de cada uno. 
Algunos descriptores de los atributos sensoriales de café

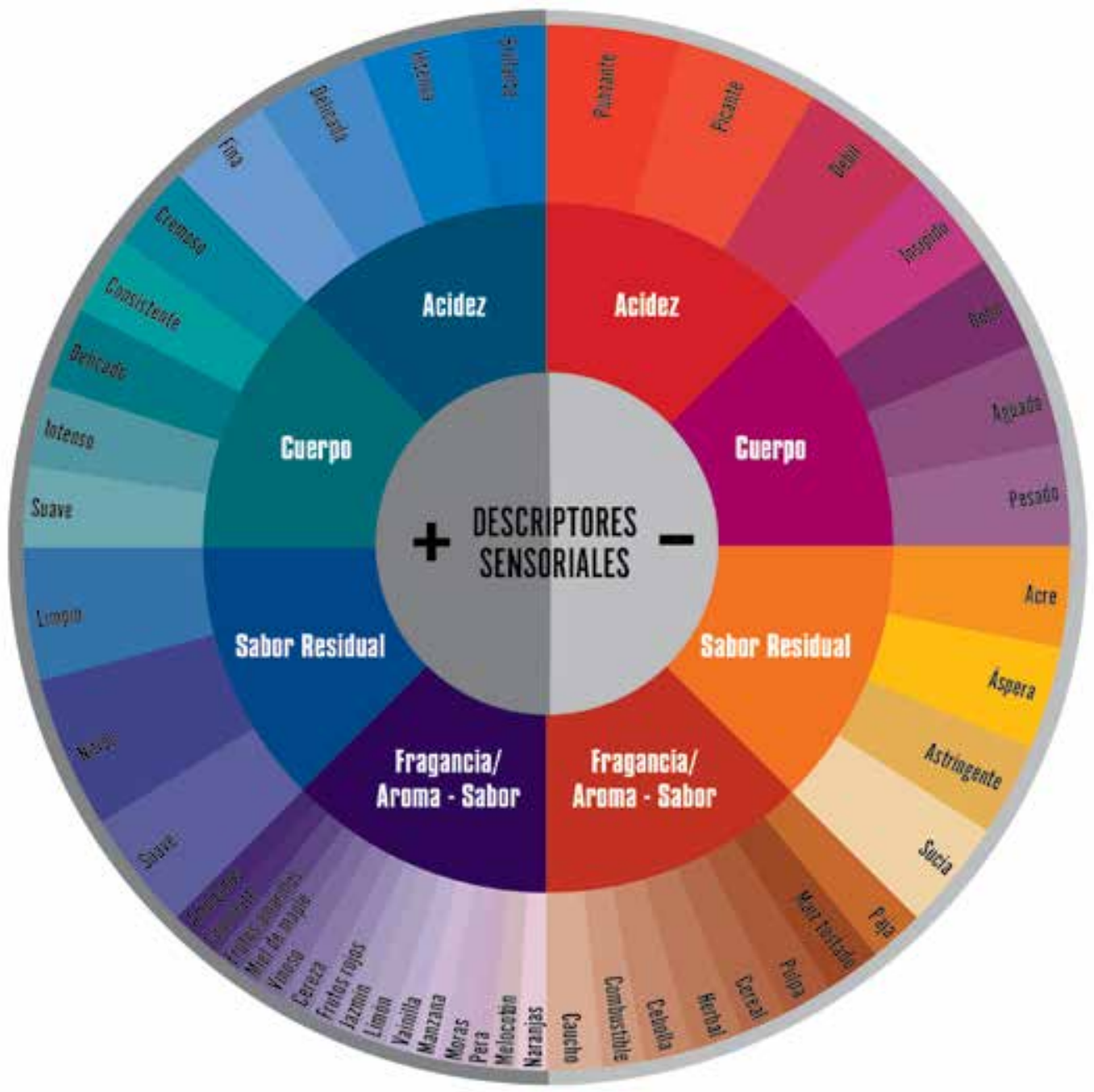




\section{Inocuidad}

La inocuidad se refiere a la inexistencia de riesgos para la salud humana y toma especial importancia en los productos destinados para el consumo, como los alimentos. Por lo tanto, es necesaria la realización de pruebas que permitan controlar dichos riesgos.

La Ocratoxina A(OTA) es una toxina producida por hongos, que tiene efectos negativos en la salud humana y que no es eliminada totalmente en el proceso de tueste. El principal hongo productor de OTA Aspergillus ochraceus, se encuentra con mayor frecuencia en el suelo, por lo tanto, el café que ha estado en contacto con este tiene un mayor riesgo. Otra fuente que puede tener una relación con mayores contenidos es la presencia de defectos físicos.

El límite de actividad de agua para el crecimiento inicial del hongo es de 0,76 , lo que corresponde a un contenido de humedad del $14,2 \%$ para los granos de café verde, pero para la producción de ocratoxina los valores mínimos de actividad de agua varían entre 0,83 y 0,87 . Lo anterior implica que para el crecimiento de hongos en el café se requiere un contenido de humedad que exceda el $13 \%$ en base húmeda. Es por este motivo que dentro de las estrategias de poscosecha se tienen las recomendaciones asociadas a la disminución rápida del contenido de humedad a través de procesos eficientes de secado y la conservación de este nivel en la cadena de comercialización.

\section{Composición química del café}

La composición química del café almendra tiene incidencia en los diferentes atributos sensoriales. La cafeína es estable al calor y se asocia generalmente con el sabor amargo distintivo del café, la trigonelina es un alcaloide cuya importancia está relacionada con su degradación durante el proceso de tueste, que genera varios compuestos volátiles que influyen en el aroma de la bebida. 


\section{Compuestos químicos del café verde}

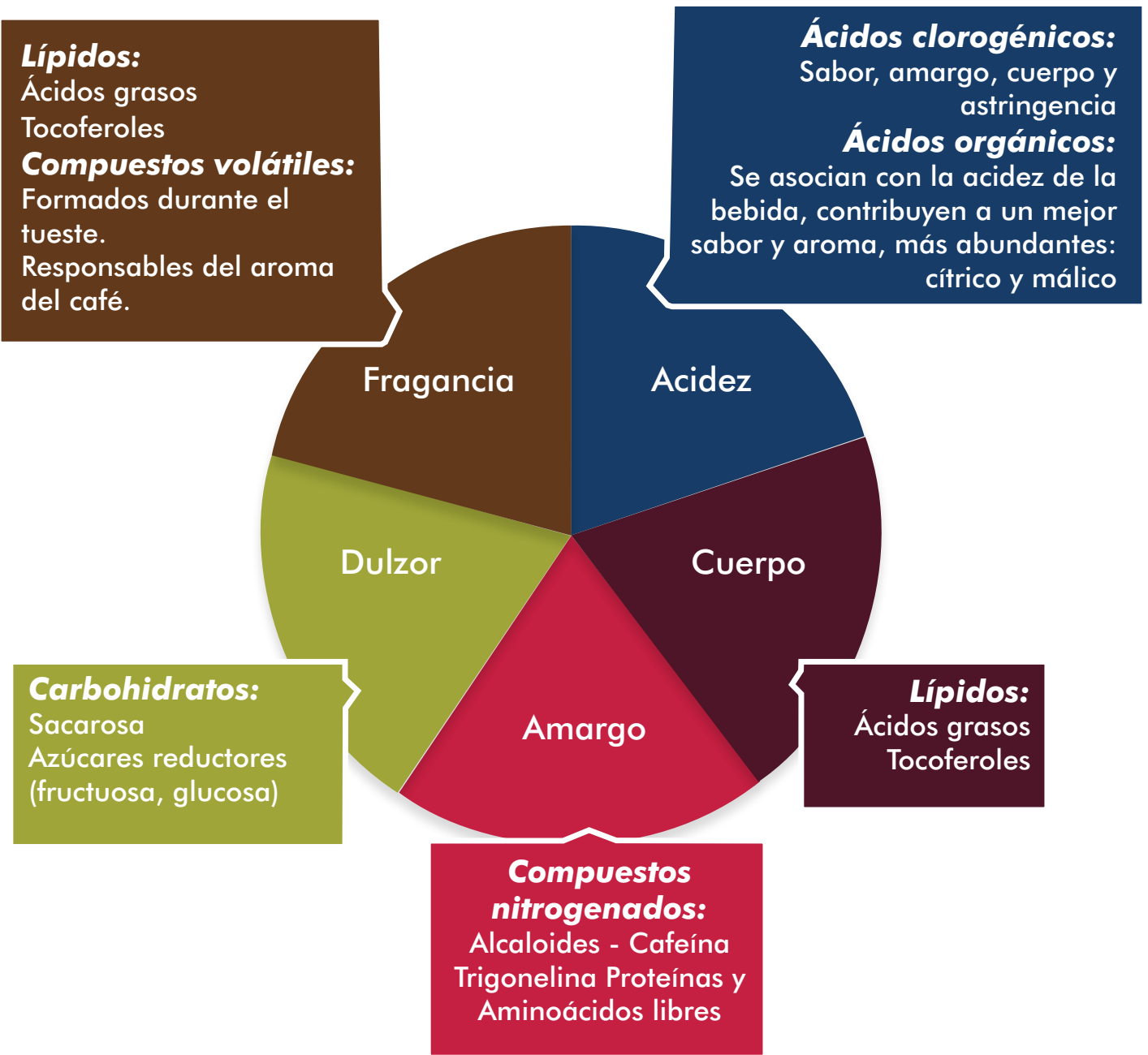


Los ácidos clorogénicos, son compuestos fenólicos, que influyen en la formación del aroma, acidez, astringencia y amargo. La sacarosa, compuesto más abundante, actúa como precursor del aroma originando varias sustancias en el proceso de tueste, afectando el sabor y aroma de la bebida. La presencia de lípidos se asocia con la duración del aroma y la espuma de la bebida, y su acumulación depende de varios factores, particularmente de la especie.

Para la obtención de café de calidad deben tenerse en cuenta todas las etapas del proceso productivo y los indicadores que permiten su valoración tales como la inocuidad, la calidad física y sensorial y la composición química. Por lo tanto, es necesario desarrollar una perspectiva global que permita integrar el efecto de la variedad, de las prácticas agronómicas y de cada una de las etapas del proceso de beneficio húmedo para lograr la máxima expresión de las cualidades sensoriales del café. 